\title{
TINGKAT KEPATUHAN ANTIHIPERTENSI DAN PENGONTROLAN TEKANAN DARAH PASIEN RAWAT JALAN RS PKU MUHAMMADIYAH BANTUL, YOGYAKARTA YANG MENDAPATKAN BRIEF COUNSELING-5A DAN SMS MOTIVASIONAL
}

\author{
Zukhruf Ginanjar Saputri*), Akrom, Endang Darmawan \\ Fakultas Farmasi, Universitas Ahmad Dahlan, Yogyakarta, Indonesia
}

Received May 23, 2016; Accepted August 19, 2016

\begin{abstract}
Antihypertensive therapy requires adherence therapy to achieve therapeutic targets such as controlling blood pressure both systolic and diastolic blood pressure. Pharmacists in counseling interventions have been developed in the form of brief Counseling - 5A and SMS reminders. But the relationship between adherence and blood pressure control is still studied and both of them are related to many factors that can affect. The aim of this study was to determine the relationship of the level of compliance antihypertensive therapy and control of blood pressure (systolic and diastolic) hypertension patients in outpatient PKU Muhammadiyah Bantul, Yogyakarta who get Brief counseling - 5A and SMS motivation.Patients who met the inclusion criteria were divided into 2 groups, the treatment group $(n=$ 30) who received Brief counseling - 5A and SMS motivation, and the control group $(n=30)$ who received usual care (conventional counseling). Data were collected by interviews using questionnaires compliance of Morisky Medication Adherence Scale (MMAS), the value of blood pressure is taken from the medical record. Correlation between level of adherence and blood pressure control have been analyzed using Fisher test. The results showed the treatment group with categories adherent patients $(n=25)$ was increase in blood pressure control by $36.67 \%$ compared with the control group of patients adherent category $(n=6)$ only $6.67 \%$ that has control of the blood pressure on post study. In contrast to patient with adherent category, who had uncontrolled blood pressure are 46.67\% (treatment group) compared to the control group $13.33 \%$ on the post study. Patients categories of non-adherent but is having control of blood pressure showed $3.33 \%$ (treatment group) and $26.67 \%$ (control group) on the post study. Although the rate of compliance in the treatment group was higher than control group on the second visit, but there was no significant relation between the level of compliance and controlling blood pressure both in control group $(p=1.000)$ and intervention group $(p=0.622)$ on the second visit (post). The rate of compliance and blood pressure control of patients with hypertensive was low. There were many factors such as poor of knowledge, drugs side effect, poly pharmacy, which related with level of compliance. There was no correlation between antihypertensive compliance and blood pressure control in hypertensive patients ambulatory PKU Muhammadiyah Bantul Hospital, who get Brief counseling - 5A and SMS motivation. Therefore it is necessary to do further research to identify factors that influence to improve patients' awareness in the management of hypertension.
\end{abstract}

Keywords: hypertension, compliance, blood pressure, Brief Counseling-5A

\section{PENDAHULUAN}

Hipertensi yang tidak terkontrol dapat meningkatkan resiko angka kematian dan kesakitan karena penyakit kardiovaskuler, cerebrovaskuler dan renal desease (Ramli Azuana, et al, 2012). WHO menyebutkan bahwa pengontrolan hipertensi yang kurang optimal (sistolik $>115 \mathrm{mmHg}$ ) dapat menyebabkan $62 \%$ penyakit cerebrovaskuler dan $49 \%$ penyakit iskemik (A Rodgers et al., 2000). Hasil Riskesdas 2013 menunjukkan prevalensi hipertensi secara nasional di Indonesia mencapai 25,8\% (Depkes RI, 2013). 
Dibutuhkan kepatuhan terapi untuk mencapai pengontrolan tekanan darah sebagai tujuan terapi (Ramli Azuana, et al, 2012). Penelitian sebelumnya menunjukkan bahwa intervensi farmasis dapat meningkatkan kepatuhan terapi dan pengontrolan tekanan darah (Mehos et al., 2000). Salah satu intervensi farmasi berupa edukasi dan konseling, bahkan motivasi dalam bentuk system reminder (SMS) juga telah dikembangkan di Afrika untuk meningkatkan kepatuhan antiretroviral (Mbuagbaw et al., 2011). Edukasi dan konseling farmasi diperlukan dalam peningkatan kepatuhan terapi. Konseling ditujukan untuk meningkatkan hasil terapi dengan memaksimalkan penggunaan obatobatan yang tepat (Rantucci, 1997).

Menurut Ambrosioni E, (2000) di dalam Ramli Azuna et al, (2012), ada beberapa faktor yang dapat mempengaruhi kepatuhan antara lain karakteristik demografi, tingkat keparahan penyakit, regimen terapi yang komplek (jumlah obat dan aturan pakai per hari), kelas terapi obat (tolerabilitas dan efek samping obat), tingkat kelupaan pasien dan kurangnya pemahaman tentang sifat penyakit (Ramli et al., 2012) (Ambrosioni et al., 2000).

Pasien hipertensi yang mencapai target pengontrolan tekanan darah menunjukkan tingkat kepatuhan yang tinggi (Ramli et al., 2012). Hasil penelitian Ramli Azuna et al, (2012) menunjukkan tingkat pengontrolan tekanan darah lebih baik dari pasien kategori patuh dari pada pasien kategori tidak patuh yang diukur menggunakan kuisioner MMAS (Morisky Medications Adherence Scale). Rerata tekanan darah sistolik pasien kategori tidak patuh $(139,50 \mathrm{mmHg} \pm 17,32)$ secara signifikan lebih tinggi dari pada pasien kategori patuh $(135,83$ $\mathrm{mmHg} \pm 15.79 ; \mathrm{t}[618]=2,815 ; 95 \% \mathrm{CI}: 1,126$ $6,217 ; \mathrm{P}=0,05)$. Sedangkan rerata tekanan darah distolik pasien kategori tidak patuh $(85,13 \mathrm{mmHg} \pm$ $8,48)$ juga lebih tinggi secara signifikan dari pada pasien kategori patuh $(83,56 \mathrm{mmHg} \pm 7,26$; $\mathrm{t}$ [600] $=2,521 ; 95 \%$ CI: 0,347-2,792; $\mathrm{P}=0,05)$.

Telah dikembangkan model konseling pada penelitian sebelumnya dengan metode brief counseling-5A disertai SMS motivasi untuk meningkatkan kepatuhan terapi antihipertensi, namun penelitian lanjutan untuk mengetahui faktor yang berpengaruh pada tingkat kepatuhan dan pengontrolan tekanan darah masih perlu dikembangkan. Berdasarkan hal tersebut, penelitian ini dilakukan untuk mengetahui hubungan tingkat kepatuhan dengan pengontrolan tekanan darah pasien hipertensi rawat jalan di RS PKU Muhammadiyah Bantul Yogyakarta.

\section{METODE PENELITIAN}

Penelitian dilakukan secara prospektif dengan desain quasi eksperimental. Penelitian dilakukan di RS PKU Muhammadiyah Bantul Yogyakarta selama bulan Januari-April 2013. Kriteria inklusi adalah pasien pasien usia 18-65 tahun baik laki-laki maupun perempuan dengan diagnosa hipertensi baik tingkat I maupun tingkat II dengan atau tanpa dislipidemia dan diabetes mellitus (DM), mendapatkan satu atau lebih dari satu obat antihipertensi, memiliki telepon genggam (handphone), tidak tuli dan tidak buta. Kriteria eksklusi adalah pasien yang sedang hamil.

Subyek yang termasuk dalam kriteria inklusi dan secara sukarela mengikuti penelitian (setelah mendapatkan informed consent) dibagi menjadi dua kelompok yaitu kelompok kontrol dan perlakuan. Kelompok kontrol mendapatkan konseling konvensional (usual care) dari apoteker rumah sakit, sedangkan kelompok perlakuan mendapatkan brief counseling - 5A dan SMS motivasi dari peneliti. Pemberian konseling dilakukan pada kunjungan pertama (pre study) dan SMS motivasi diberikan setiap hari hingga kunjungan kedua (post study).

Pengumpulan data dilakukan dengan wawancara kuisioner kepatuhan Morisky Medication Adherence Scale (MMAS) (Morisky et al., 2008), sedangkan data tekanan darah diambil dari catatan rekam medis. Skor MMAS $=8$ termasuk kategori patuh sedangkan skor $<8$ kategori tidak patuh. Pengontrolan tekanan darah mengacu dari JNC 8 yaitu untuk usia $<60^{\text {th }}$ tekanan darah $<140 /<90$ mmHg termasuk kategori terkontrol, sebaliknya jika $>140 />90 \mathrm{mmHg}$ kategori tidak terkontrol), sedangkan untuk usia $>60^{\text {th }}$ tekanan darah $<150 / 90 \mathrm{mmHg}$ termasuk kategori terkontrol dan $>150 / 90 \mathrm{mmHg}$ termasuk kategori tidak terkontrol. Analisis statistik untuk mengetahui hubungan tingkat kepatuhan dengan pengontrolan tekanana 
darah menggunakan uji chi square (jika tidak memenuhi menggunakan uji Fisher).

\section{HASIL DAN PEMBAHASAN}

Subyek yang masuk dalam krteria inklusi sejumlah 60 pasien dibagi menjadi kelompok kontrol $(n=30)$ dan kelompok perlakuan $(n=30)$. Kelompok kontrol mendapatkan konseling usual care dari apoteker rumah sakit, sedangakan kelompok perlakuan mendapatkan brief counseling - 5A dan SMS motivasi. Data hasil karakteristik responden baik kelompok kontrol dan perlakuan dapat dilihat pada Tabel I.

Karakteristik responden berdasarkan jenis kelamin $(\mathrm{P}=0,604)$, usia $(\mathrm{P}=0,619)$, pendidikan $(\mathrm{P}=$ $0,423)$, dan riwayat hipertensi $(\mathrm{p}=0,097)$ menunjukkan nilai $\mathrm{p}>0,05$, hal ini menunjukkan tidak ada perbedaan yang bermakna antara kedua kelompok baik kontrol dan perlakuan. Mayoritas responden adalah perempuan baik pada kelompok kontrol $(70,0 \%)$ dan kelompok perlakuan $(73,3 \%)$. Usia yang mendominasi adalah pada rentang usia $50-59^{\text {th }}$ baik kelompok kontrol $(53,3 \%)$ dan perlakuan $(43,3 \%)$. Pendidikan mendominasi pada pendidikan usia 0-9 tahun baik kelompok kontrol $(66,7 \%)$ dan perlakuan $(46,7 \%)$. Kelompok kontrol mayoritas tidak ada riwayat hipertensi (70\%) sedangkan kelompok perlakuan $(66,7 \%)$ ada riwayat hipertensi.

Rerata tekanan darah dari kelompok kontrol dan perlakuan berdasarkan tingkat kepatuhan pada pre study dan post study dapat dilihat di Tabel II.

Tabel 1. Karakteristik Responden Penelitian Pasien Hipertensi di RS PKU Muhammadiyah Bantul Yogyakarta

\begin{tabular}{|c|c|c|c|c|c|}
\hline \multirow{2}{*}{$\begin{array}{l}\text { Karakteristik } \\
\text { Pasien }\end{array}$} & \multicolumn{2}{|c|}{ Kelompok Perlakuan } & \multicolumn{2}{|c|}{ Kelompok Kontrol } & \multirow[t]{2}{*}{$P$} \\
\hline & $\begin{array}{c}\text { Jumlah } \\
(\mathbf{n}=30)\end{array}$ & $\%$ & $\begin{array}{c}\text { Jumlah } \\
(\mathbf{n}=\mathbf{3 0})\end{array}$ & $\%$ & \\
\hline \multicolumn{6}{|l|}{ Jenis Kelamin } \\
\hline Laki-laki & 8 & 26,7 & 9 & 30,0 & 0,604 \\
\hline Perempuan & 22 & 73,3 & 21 & 70,0 & \\
\hline \multicolumn{6}{|l|}{ Usia (tahun) } \\
\hline $18-29$ & & & & & 0,619 \\
\hline $30-39$ & 1 & 3,3 & & & \\
\hline $40-49$ & 9 & 30,0 & 5 & 16,7 & \\
\hline $50-59$ & 13 & 43,3 & 16 & 53,3 & \\
\hline $60-65$ & 7 & 23,3 & 9 & 30,0 & \\
\hline \multicolumn{6}{|l|}{ Pendidikan } \\
\hline 0-9 tahun & 14 & 46,7 & 20 & 66,7 & 0,423 \\
\hline 10-12 tahun & 8 & 26,7 & 6 & 20,0 & \\
\hline$>12$ tahun & 8 & 26,7 & 4 & 13,3 & \\
\hline \multicolumn{6}{|l|}{ Riwayat Hipertensi } \\
\hline Ada & 20 & 66,7 & 9 & 30,0 & \\
\hline Tidak ada & 10 & 33,3 & 21 & 70,0 & 0,097 \\
\hline
\end{tabular}

Keterangan: uji korelasi Pearson untuk data parametrik, uji korelasi Spearman untuk data non parametrik.

Tabel II. Rerata Tekanan Darah Sistolik dan Diastolik Kelompok Kontrol dan Perlakuan Pasien Hipertensi Rawat Jalan pada Kunjungan Pertama (post study) dan Kunjungan Kedua (post study)

\begin{tabular}{llllllll}
\hline Kelompok & $\begin{array}{l}\text { Tingkat } \\
\text { kepatuhan }\end{array}$ & $\mathrm{N}$ & $\begin{array}{l}\text { Sistolik } \\
\text { (mean } \pm \text { SD) }\end{array}$ & $\begin{array}{l}\text { Diastolik } \\
(\text { mean } \pm \text { SD) }\end{array}$ & N & $\begin{array}{l}\text { Sistolik } \\
\text { (mean } \pm \text { SD) }\end{array}$ & $\begin{array}{l}\text { Diastolik } \\
(\text { mean } \pm \text { SD) }\end{array}$ \\
\cline { 2 - 7 } Kontrol & Tidak patuh & 25 & $147,44 \pm 21,7$ & $83,12 \pm 11,01$ & 24 & $144,5 \pm 16,37$ & $83,13 \pm 8,82$ \\
& Patuh & 5 & $154,00 \pm 16,7$ & $87,00 \pm 4,47$ & 6 & $158,33 \pm 33,11$ & $84,17 \pm 12,00$ \\
& & & & & & & \\
Perlakuan & Tidak patuh & 18 & $156,67 \pm 17,8$ & $90,56 \pm 11,6$ & 5 & $140,00 \pm 18,70$ & $90,00 \pm 18,70$ \\
& Patuh & 12 & $148,83 \pm 22,11$ & $88,50 \pm 8,40$ & 25 & $137,8 \pm 17,79$ & $81,60 \pm 7,46$ \\
\hline
\end{tabular}

Keterangan: tidak patuh $(<8)$; patuh $(=8)$ 
Tabel III. Hubungan tingkat kepatuhan dan pengontrolan tekanan darah kelompok kontrol pasien hipertensi rawat jalan pada kunjungan pertama (post study) dan kunjungan kedua (post study)

\begin{tabular}{|c|c|c|c|c|}
\hline \multirow{2}{*}{$\begin{array}{l}\text { Pengambilan } \\
\text { data }\end{array}$} & \multirow[t]{2}{*}{ Tingkat kepatuhan } & \multicolumn{2}{|c|}{ TD (TDD/TDS) } & \multirow[t]{2}{*}{$\mathbf{P}$} \\
\hline & & Terkontrol & tidak terkontrol & \\
\hline \multirow[t]{3}{*}{ Pre } & Tidak patuh $(<8)$ & $8(26,67 \%)$ & $17(56,67 \%)$ & \multirow[t]{3}{*}{0,287} \\
\hline & Patuh $(=8)$ & $0(0 \%)$ & $5(16,67 \%)$ & \\
\hline & Total & 8 & 22 & \\
\hline \multirow[t]{3}{*}{ Post } & Tidak patuh $(<8)$ & $8(26,67 \%)$ & $16(53,33 \%)$ & \multirow[t]{3}{*}{1,000} \\
\hline & Patuh $(=8)$ & $2(6,67 \%)$ & $4(13,33 \%)$ & \\
\hline & Total & 10 & 20 & \\
\hline
\end{tabular}

Keterangan: Tekanan darah (TDD/TDS) terkontrol usia $<60^{\text {th }}:<140 /<90 \mathrm{mmHg}$; Usia $>60^{\text {th }}$ : $<150 /<90 \mathrm{mmHg}$ (JNC 8); uji Fisher p<0,05 signifikan

Tabel IV. Hubungan tingkat kepatuhan dan pengontrolan tekanan darah kelompok perlakuan pasien hipertensi rawat jalan pada kunjungan pertama (post study) dan kunjungan kedua (post study)

\begin{tabular}{|c|c|c|c|c|}
\hline \multirow{2}{*}{$\begin{array}{l}\text { Pengambilan } \\
\text { data }\end{array}$} & \multirow[t]{2}{*}{ Tingkat kepatuhan } & \multicolumn{2}{|c|}{ TD (TDD/TDS) } & \multirow[t]{2}{*}{$\mathbf{P}$} \\
\hline & & Terkontrol & Tidak terkontrol & \\
\hline \multirow[t]{3}{*}{ Pre } & Tidak patuh $(<8)$ & $2(6,67 \%)$ & $16(53,33 \%)$ & \multirow[t]{3}{*}{1,000} \\
\hline & Patuh $(=8)$ & $2(6,67 \%)$ & $10(33,33 \%)$ & \\
\hline & Total & 4 & 26 & \\
\hline \multirow[t]{3}{*}{ Post } & Tidak patuh $(<8)$ & $1(3,33 \%)$ & $4(13,33 \%)$ & \multirow[t]{3}{*}{0,622} \\
\hline & Patuh $(=8)$ & $11(36,67 \%)$ & $14(46,67 \%)$ & \\
\hline & Total & 12 & 18 & \\
\hline
\end{tabular}

Keterangan : Tekanan darah (TDD/TDS) terkontrol usia $<60^{\text {th }}:<140 /<90 \mathrm{mmHg}$; Usia $>60^{\text {th }}$ : $<150 /<90 \mathrm{mmHg}$ (JNC 8); uji Fisher p<0,05 signifikan

Kelompok kontrol terdapat 25 pasien dengan kategori tidak patuh pada pre study dan menjadi 24 pada post study dengan rerata tekanan darah sistolik dari $147,44 \pm 21,7 \quad(\mathrm{mmHg})$ menjadi $144,5 \pm 16,37$ $(\mathrm{mmHg})$ dan rerata tekanan darah diastolik dari $83,12 \pm 11,01$ (mmHg) menjadi $83,13 \pm 8,82(\mathrm{mmHg})$. Sedangkan kategori patuh terdapat 5 pasien pada pre study dan menjadi 6 pasien pada post study dengan rerata tekanan darah sistolik $154,00 \pm 16,7$ $(\mathrm{mmHg})$ menjadi $158,33 \pm 33,11(\mathrm{mmHg})$ dan rerata tekanan darah diastolik dari $87,00 \pm 4,47(\mathrm{mmHg})$ menjadi 84,17 $\pm 12,00$ (mmHg).

Kelompok perlakuan terdapat 18 pasien kategori tidak patuh pada pre study dan berkurang menjadi 5 pasien pada post study dengan rerata tekanan darah sistolik dari $156,67 \pm 17,8(\mathrm{mmHg})$ turun menjadi $140,00 \pm 18,70(\mathrm{mmHg})$ begitu juga rerata tekanan darah diastolik dari 90,56 $\pm 11,6$ (mmHg) menjadi 90,00 $\pm 18,70$ (mmHg). Sedangkan kategori patuh terdapat 12 pasien pada pre study meningkat menjadi 25 pasien pada post study dengan rerata tekanan darah sistolik $148,83 \pm 22,11$ (mmHg) menjadi $137,8 \pm 17,79(\mathrm{mmHg})$ dan rerata tekanan darah diastolik dari $88,50 \pm 8,40(\mathrm{mmHg})$

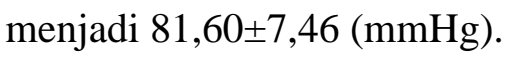

Hubungan antara tingkat kepatuhan dan pengontrolan tekanan darah baik kelompok kontrol dan perlakuan dapat dilihat di Tabel III dan Tabel IV.

Apabila dihubungkan dengan pengontrolan tekanan darah (TD) kelompok kontrol pada pre study menunjukkan bahwa pada pasien yang tidak patuh terdapat $26,67 \%$ yang mengalami pengontrolan TD, sedangakan sebanyak $56,67 \%$ dari pasien yang tidak patuh dengan TD yang tidak terkontrol. Sebaliknya pada pasien kategori patuh terdapat $16,67 \%$ yang TD tidak terkontrol dengan nilai $\mathrm{p}=0,287$. Pada post study menunjukkan sebanyak $26,67 \%$ pasien mengalami pengontrolan TD pada kategori pasien tidak patuh, dan sebanyak $53,33 \%$ mengalami TD tidak terkontrol. Sebanyak $6,67 \%$ pasien mengalami TD terkontrol dan $13,37 \%$ tidak terkontrol pada kategori pasien patuh $(\mathrm{p}=1,000)$.

Kelompok perlakuan pada pre study menunjukkan $6,67 \%$ pasien mengalami TD 
terkontrol, dan 53,33\% TD tidak terkontrol dari pasien kategori tidak patuh. Sebaliknya pada kategori pasien patuh terdapat $6,67 \%$ mengalami TDterkontrol, dan 33,33\% tidak terkontrol $(\mathrm{p}=1,000)$. Sedangkan pada post study menunjukkan sebanyak 3,33\% pasien mengalami TD terkontrol, dan 13,33\% TD terkontrol dari pasien kategori tidak patuh. Sebaliknya pada kategori pasien patuh terdapat $36,67 \%$ mengalami pengontrolan TD dan $46,67 \%$ TD tidak terkontrol dengan nilai $\mathrm{p}=0,622$.

Kepatuhan terapi telah banyak diteliti dan dihubungkan dengan faktor-faktor penting dalam pengontrolan tekanan darah pasien hipertensi. Kepatuhan terapi pada menejemen hipertensi dilaporkan berbeda-beda dari penelitian yang sudah ada, hal ini tergantung dari metode, jumlah pasien, definisi kepatuhan dan pengukuran kepatuhan dari masing-masing penelitian (Ramli et al., 2012). Penelitian ini menggunakan instrumen kuisioner kepatuhan yang telah banyak digunakan di beberapa Negara yaitu kuisioner MMAS. Sedangkan kepatuhan disini diartikan jika nilai skor MMAS adalah 8 , sedangkan jika kurang dari $8(<8)$ maka dikategorikan tidak patuh.

Kelompok perlakuan $(83,33 \%)$ menunjukkan prosentase yang lebih besar pada kategori patuh daripada kelompok kontrol (20\%) pada kunjungan kedua setelah diberikan brief counselling-5A serta SMS motivasional. Dengan rerata tekanan darah sistolik $137,8 \pm 17,79 \mathrm{mmHg}$ dan diastolik $81,60 \pm 7,46 \mathrm{mmHg}$. Hal ini sesuai dengan target pengontrolan tekanan darah berdasarkan JNC 8 dimana sistolik <140mmHg dan diastolik $<90 \mathrm{mmHg}$. Hal ini menunjukkan dengan adanya brief counseling-5A dan SMS motivasional dapat meningkatkan kepatuhan dan pengontrolan tekanan darah. Hal ini sejalan dengan penelitian Ramanath, et, al (2012) yang menunjukkan bahwa pemberian intervensi farmasi dapat meningkatkan kepatuhan dan kualitas hidup.

Peningkatan kepatuhan dan pengontrolan tekanan darah yang terjadi pada masing-masing kelompok baik kontrol dan perlakuan dianalisis kembali menggunakan uji fisher untuk melihat ada atau tidaknya hubungan kedua variable. Walaupun terjadi peningkatan pada tingkat kepatuhan dan pengontrolan tekanan darah pada kelompok intervensi (post study) namun tidak ada hubungan bermakna antara tingkat kepatuhan dan pengontrolan tekanan darah pada kedua kelompok. Hal ini ditunjukkan dari nilai $p>0,05$ baik kelompok kontrol $(\mathrm{p}=1,000)$ dan perlakuan $(\mathrm{p}=0,622)$ pada kunjungan kedua (post). Hal ini berlawanan dengan penelitian sebelumnya yang menunjukkan hubungan positif antara kepatuhan dan pengontrolan tekanan darah (Yiannakopoulou et al., 2005).

Penelitian untuk melihat faktor yang berpengaruh pada kepatuhan dengan metode pill count telah dilakukan dan menunjukkan bahwa tingkat kepatuhan meningkat namun pengontrolan tekanan darah tidak adekuat pada kategori pasien tidak patuh (Al Meza et al., 2009). Hasil serupa dalam penelitian ini pada pasien kategori tidak patuh baik kelompok kontrol dan perlakuan menunjukkan pengontrolan tekanan darah yang tidak adekuat. Hal ini dapat dipengaruhi beberapa faktor termasuk metode yang digunakan dalam mengukur kepatuhan dengan kuisioner MMAS. Pengukuran dengan kuisioner masih sulit untuk dipastikan ke akuratannya untuk responden dimana karakteristik demografi mayoritas adalah masyarakat urban. Diperlukan pengukuran tambahan sebagai sampling seperti pill count untuk membuktikan apakah pasien benar benar patuh atau tidak. Kultur budaya masyarakat Indonesia khususnya masyarakat urban cukup memberikan pengaruh terhadap kooperatif dan kesadaran baik dalam menjawab kuisioner ataupun menejemen hipertensi, berbeda dengan kultur budaya Negara-Negara maju yang sudah memiliki kesadaran dalam menejemen hipertensi (Jennita $\mathrm{G}$ et al., 2015). Model kuisioner MMAS yang telah disusun dengan model jawaban "ya" dan "tidak" juga berpengaruh terhadap persepsi masyarakat dalam menjawab khususnya untuk mayoritas masyarakat urban, masih perlu penggalian informasi untuk menilai perilaku pasien.

Faktor lain yang dapat mempengaruhi tingkat kepatuhan adalah adanya efek samping dari obat yang diresepkan. Hal ini ditunjukkan dari beberapa jawaban pasien saat menjawab kuisioner, yang 
menyatakan bahwa adanya efek samping jangka panjang seperti gangguan ginjal membuat persepsi pasien untuk tidak rutin minum obat. Banyaknya jumlah obat yang diresepkan dan pengaturan dosis yang lebih dari satu kali sehari juga mempengaruhi kepatuhan pasien. Hal ini digali secara kualitatif saat wawancara dengan pasien. Hal ini sejalan dengan penelitian Al-Meza, Amal et al, (2009) dan Morisky, et al, (2008). Oleh karena itu perlu dilakukan penelitian lanjutan untuk mengidentifikasi faktor yang berpengaruh terhadap kepatuhan guna meningkatkan kesadaran pasien dalam menejemen hipertensi sehingga tujuan terapi dapat tercapai. Serta perlu dilakukan penelitian lanjutan dengan tambahan metode untuk pengukuran kepatuhan pasien seperti pill count.

\section{KESIMPULAN}

Tidak terdapat hubungan antara kepatuhan antihipertensi dan pengontrolan tekanan darah pasien hipertensi rawat jalan di PKU Muhammadiyah Bantul, Yogyakarta yang mendapatkan brief counseling-5A dan SMS motivasi. Hal ini dikarenakan beberapa faktor yang mempengaruhi seperti rendahnya pengetahuan, adanya efek samping obat, dan polifarmasi.

\section{DAFTAR PUSTAKA}

A Rodgers, C, L., S, M., 2000. Reducing the global burden of blood pressure-related cardiovascular disease. J. Hypertens. Suppl. Off. J. Int. Soc. Hypertens. 18, S3-6.

Al-Mehza, A.M., Al-Muhailije, F.A., Khalfan, M.M., and Al-Yahya, A.A., 2009. Drug compliance among hypertensive patients; an area based study. European Journal of General Medicine, 6 (1), 6-10.

Ambrosioni, E., Leonetti, G., Pessina, A.C., Rappelli, A., Trimarco, B., Zanchetti, A., 2000. Patterns of hypertension management in Italy: results of a pharmacoepidemiological survey on antihypertensive therapy. Scientific Committee of the Italian Pharmacoepidemiological Survey on
Antihypertensive Therapy. J. Hypertens. 18, 1691-1699.

Meinema, J.G., Dijk, N., Beune, E.J.A.J., Jaarsma, D.A.D.C., Van Weert, H.C.P.M., Haafkens, J.A., and Zeeb, H., 2015. Determinants of adherence to treatment in hypertensive patients of African descent and the role of culturally appropriate education. PLoS ONE, 10 (8).

Kemenkes, 2013. Riset Kesehatan Dasar 2013. Badan Penelitian dan Pengembangan Kesehatan, Kementrian Kesehatan RI, Jakarta.

Mbuagbaw, L., Thabane, L., Ongolo-Zogo, P., Lang, T., 2011. The challenges and opportunities of conducting a clinical trial in a low resource setting: the case of the Cameroon mobile phone SMS (CAMPS) trial, an investigator initiated trial. Trials 12, 145.

Mehos, B.M., Saseen, J.J., MacLaughlin, E.J., 2000. Effect of Pharmacist Intervention and Initiation of Home Blood Pressure Monitoring in Patients with Uncontrolled Hypertension. Pharmacother. J. Hum. Pharmacol. Drug Ther. 20, 1384-1389.

Morisky, D.E., Ang, A., Krousel-Wood, M., Ward, H.J., 2008. Predictive validity of a medication adherence measure in an outpatient setting. J. Clin. Hypertens. Greenwich Conn 10, 348-354.

Rantucci, MJ., 2007. Komunikasi Apoteker-Pasien (Edisi 2). Penerjemah: A. N. Sani. Jakarta: Penerbit Kedokteran EGC.

Ramli, A., Ahmad, N.S., Paraidathathu, T., 2012. Medication adherence among hypertensive patients of primary health clinics in Malaysia. Patient Prefer. Adherence 6, 613.

Yiannakopoulou, E.C., Papadopulos, J.S., Cokkinos, D.V., Mountokalakis, T.D., 2005. Adherence to antihypertensive treatment: a critical factor for blood pressure control. Eur. J. Cardiovasc. Prev. Rehabil. 12, 243249. 